\title{
Challenges of the Citrus Industries Along the Northern Coastal Fringe of the Gulf of Mexico in the Southeastern United States: Introduction to the Workshop
}

\author{
Robert C. Ebel ${ }^{1}$ \\ Department of Horticulture, Auburn University, 101 Funchess Hall, Auburn, Alabama 36849
}

The satsuma mandarin industry in the southeastern United States dates back to the late $1800 \mathrm{~s}$, but growth has been limited, principally as a result of extreme climatic events. Recent efforts by researchers and industry personnel in this region are coordinating activities to aid expansion of the industry. The most consistent limitation to industry expansion has been freeze stress. More recently, however, warmer water tem- peratures in the Atlantic and Gulf of Mexico have fueled hurricanes that cause wind, flooding, and salt injury. Hurricane Katrina is an example of the impact that hurricanes can have as evidenced by its devastating impact of the Satsuma industry from Louisiana to Alabama. Development of the industry will also require concomitant development of markets and production methods that are suitable to the regional climate and soil type. This workshop discussed the risk of freezes and hurricanes, and practices that mitigate injury by these extreme climatic events. We also discussed marketing research that has led to market identification and segments within markets that would optimize sale and profitability of Satsuma mandarins. The current status of production practices and research that still needs to be conducted to optimize yield and fruit quality was also discussed. 